\title{
6. The public right to know about science
}

\begin{abstract}
Journalism and science are two vocational occupations with roots deep in the momentous developments that ushered in the modern era (eg, Reformation, Enlightenment, democracy and the nation state). While science arises from the former, professional journalists remain committed to their role as the 'watchdogs' of democracy. While this has normally meant scrutiny of the acts of public figures like politicians and entrepreneurs, increasingly in late modernity attention has been turned to science and its potential for harm (eg, nuclear technology, genetic manipulation, etc.).
\end{abstract}

ROSSLYN REED

University of Technology, Sydney

CIENCE writers and journalists have seen their role more as educators and promoters of science in the public arena than as critics and interrogators of scientists and their work. Other journalists have been ambivalent at best about science reporting. With changes in the nature of scientific endeavour which blur boundaries between 'pure' and 'applied', public and corporate as well as 'mainstream' and pseudo-science, there is a need for an informed public to ensure democratic participation and decision making about the myriad ways in which scientific practice and products impact on lives and livelihoods. While this may be in terms of their role as citizens, social impacts of science can also affect the public as consumers.

This article takes up questions about the extent and type of journalistic 
THE PUBLIC RIGHT TO KNOW

practice which might go some way to ensuring more informed public debate and decision-making in relation to science (and technology). It notes both developments and decline in the reporting of science and considers when and why investigative journalism can help or hinder public understanding of science, its benefits and costs.

\section{Background and context}

Science is no longer confined to the select few, if it ever was. Two to three hundred years ago it was a branch of philosophy, natural philosophy, pursued by higher status 'gentlemen' sometimes assisted by wives, sisters and daughters. The results of their theories and observations were disseminated through learned societies within and across national boundaries but included a degree of competition for acclaim on the basis of class and nationality (see Sobel, 1996; Winchester, 2001) as well as sex (see Alic, 1986;Wertheim, 1995). Since then science has become a field of study in its own right and fragmented into disciplines each with their own learned societies and peer reviewed journals. It has become institutionalized in universities and institutes and of major interest to governments seeking strategic, developmental and commercial advantage. Especially since the turn of the twentieth century science has been linked to commodity production as a source of increasing profit. With increasing linkages between governments, institutions and corporations comes greater secrecy as in 'commercial-in-confidence' provisions and limited public access to new scientific knowledge (see Lloyd-Smith, 2002). Constraints on full and open public debate coincide with increasing scientific impact on everyday life and access to livelihood for societies as a whole.

Among scientists, science educators and communicators there is a call for more 'public awareness of science'. This is usually part of a desire to increase public knowledge and understanding of the benefits of science and to promote science education and careers. Despite its privileged status as a form of knowledge in late modernity, science has been increasingly criticized for its potential for harm (eg, nuclear technology, genetic manipulation, environmental degradation) with a loss of community support and interest (Perlman, 1974; Tumber, 1993). The call for public awareness of science occurs in developed countries in relation to generating better government support and funding for research as well as recognition of the contribution of science to the public good. In Australia it has succeeded in initiatives such as the 'Prime Minister's Prize for Science' and 'Prime Minister's Prize for Excellence in Science 
Teaching' (Smith, 2003). It has been less successful in providing the kind of public support for 'pure' scientific research in universities and institutes that lobbyists are aiming for, although some initiatives such as funding Australian scientists with international reputations to return 'home' have been instituted. In 'developing' countries it includes awareness of the benefits of, for example, smokeless fuel stoves and the potential of indigenous know-how. It extends also to protecting rights to benefit from the commercial exploitation of indigenous plants. Other aspects in this context include the education of women in mathematics and science and recognising their role as providers of food and consumers of scientific knowledge. While 'public awareness of science' is intended to promote science and celebrate scientific achievement, it also has potential to critique science and its costs.

Public awareness of science is not the same as a public science debate, but it could contribute to it. For debate to be meaningful or promote social welfare (in its highest and broadest sense), it needs to be informed. Currently that is most likely to involve the mainstream media - radio, television and print. There is also the potential of the internet but at this stage some knowledge and interest would be a pre-requisite to engagement there. Internet debate is probably most likely amongst activists in various campaigns. In the remainder of this paper I will outline the media impediments to debates which could engage a broad cross-section of the community within a nation state. This is not to devalue wider international debates but there are limits to what can be covered in one article. I will also outline some signs of potential for greater public understanding of scientific developments as a basis for democratic participation in scientific decision-making. The focus is on the types and extent of journalistic practice as well as scientists' views and approaches to the media.

\section{Parties/players in media science}

Science and journalism are vocational occupations that emerged from the turbulent events that ushered in modernity: the Reformation, Enlightenment, democracy and the nation state. If science owes most to the former two, journalism is linked to the latter. Science's privileged place in modernity is based on its claims to 'objective' empirical knowledge of the universe in place of religious dogma and its technologies of 'modest witnessing' which simultaneously buttressed and obscured the class, status and masculine gendered nature of scientists and science (Haraway, 1997: 23-33). The highest status scientific discipline (ie, physics) has inherited the mantle of a religious 
priesthood (Wertheim, 1995). Nevertheless, science as a whole carries some of this mystique as the public is more likely to 'believe in' the power of science to resolve problems and dilemmas rather than to understand it. While many contemporary scientists are unlikely to be aware of their historical origins and have taken on the modest witness identity unconsciously and assume a selfeffacing, even media-shy persona, some 'elite' scientists use their position to avoid interactions with those such as science journalists who might make their knowledge more accessible to lay audiences (Hermanowicz, 1998). Faith in science is more likely to be associated with ignorance of detailed scientific knowledge and even antipathy towards science based on experiences of school science curriculum and/or teaching methods (Rensberger, 2000). Some acquaintance with applications of scientific knowledge such as nuclear weapons or power may well generate a loss of faith in science and lead to distrust and criticism if not hostility.

Journalism has its roots deep in those developments that accompanied the emergence of democracy and claims allegiance to 'objectivity' in reporting, the 'freedom of the press', 'Fourth Estate' and the protection of sources from powerful interests in the interests of 'truth-telling'. They claim a commitment to scrutiny of the public actions of public individuals and institutions as the 'watchdogs' of democracy. This critical role gained ascendancy with 'muckraking' journalism in the early twentieth century and achieved prominence with the burst of investigative journalism following the United States' (US) Watergate scandal (Downie, 1976). Many young journalists would be more familiar with this model of journalism than with its history which is unlikely to be to the forefront when engaged in translating their research into public information. This has created a considerable focus on politics and political reporting. Without resorting to a simplistic assertion about 'two cultures' and recognising the diverse educational backgrounds of journalists in late modernity, many if not most journalists would share a degree of ignorance if not antipathy towards scientific topics and issues. If unavoidably linked to other potential stories they are required to do, they will cover scientific aspects sketchily or in an uninformed way. This is the basis of much tension and conflict between scientists and journalists (see Reed, 2001, for a detailed discussion). The exception here is specialist science journalists/writers who have a direct focus on science.

Science communicators/writers/journalists are sometimes practicing and/ or academic scientists or others with qualifications in science and communi- 
cation/journalism (Burns, 2001). They are generally enthusiastic communicators and promoters of awareness of science and its progressive potential and advocates of science education and careers for young people. Some scientists (among others) see science journalism (in general) as being overly simplistic and underestimating the audience. One recent television reviewer enthusiastic about a science documentary praised the makers for not treating the audience 'as six-year-olds with ADD [Attention Deficit Disorder] to make science interesting' (Zuel, 2003). This 'dumbing down' of scientific knowledge results from confusing the public average reading age of 12 years with writing for 12-year-olds. As Busch (2001) points out, the average 12-year-old understands complex concepts when presented accessibly as distinct from simplistically.

Those science writers who identify as journalists in particular are likely to include a critique of science and scientific developments in their work but in debates that threaten the status and prestige of science and its superiority as knowledge, they are likely to remain firmly in the pro-science group. Nevertheless a major contribution to public knowledge of science comes from specialist science writers/communicators in print and electronic media. At the same time, commercialisation and concentration of media ownership including the segmentation of audiences ensures that this contribution is received unevenly and unequally across social groups. While the accessibility and adequacy of these contributions are open to criticism, not all the 'best' reporting is to be found in the 'quality' media; some tabloid reports (and commercial news and current affairs items) are both succinct and informative (Reed, 2002). While there are reports of US media cutting back science coverage (Hotz, 2002), there are some signs of recent expansion in Australia (eg, Science \& Health supplement in the Sydney Morning Herald).

As a result of past tensions between journalists and scientists and criticisms of the extent and quality of science reporting, much media science is now the outcome of a double mediation. That is, science communication specialists are employed by universities and institutes to coach media-shy 'modest witnesses' in strategies and techniques to engage journalists (and publics) to enhance science reporting. This is not necessarily 'bad' if we consider the possible contribution of media-naivety of an experienced scientist like Britain's weapons expert Dr David Kelly to his alleged suicide (see Henderson, 2003). Public relations (PR) professionals are also engaged in promoting scientists and other academic staff and their scholarship to and through the 


\section{THE PUBLIC RIGHT TO KNOW}

media. This does appear to have increased at the same time as more private/ corporate funding of science has entered universities and institutes, blurring traditional divisions between pure/applied and public/private research. Nevertheless there are those in the media who advocate more professional contributions from the public sector while deploring slick packages from the private sector (Walker, 2000). Public relations 'spin', however, reaches its peak in corporate PR consultancies working mainly with large multinational corporations and this moves well beyond promoting individuals and coaching them in presentation and media style. It is at its most virulent in the outpourings of pseudo-scientific organisations like the Tobacco Institute which present fake or junk science - dubious research clothed in the forms and structure of scientific discourse - to cast doubt on the 'mainstream' scientifically established harmful effects of cigarettes (and other commodities) with a clear intent to mislead the public.

While the PR activities of commercial enterprises with their main eye to profit regardless of public welfare clearly invite a high degree of scrutiny, the blurred boundaries between the public sector (universities, institutes, governments, bureaucracies) and the private mean that all scientific developments and knowledge are potentially affected by commercial interests. This means that much more science is 'commercial-in-confidence' or even suppressed, signaling a role for greater scrutiny by science and other journalists. Not all academic scientists will achieve the degree of support achieved by Dr Nancy Olivieri of the University of Toronto when she attempted to dissent publicly (Rosenfeld, 2003). Given their backgrounds and experience, science journalists are the best qualified to bring these stories into the public domain. That does not mean, however, that all or even most scientists/academics are likely to acquiesce to the demands of funding bodies or that every science story is necessarily a topic for investigative journalism techniques in the first instance in order to facilitate democratic participation in scientific decision-making.

As a result of the frequently unrecognised divergent vocational backgrounds of journalists and scientists (with science communicators straddling the divide), their professional techniques, moral commitments and complex social, political and economic interests, the reporting and media scrutiny of scientific knowledge and developments in late modernity is a process fraught with tension, occasional conflict and a latent dissatisfaction. Most proposed remedies (see Hartz \& Chappell, 1997; cf. Peters, 1993; 1995 for alternatives) fall far short of solutions (if there are any), yet they are reasserted with each 
THE PUBLIC RIGHT TO KNOW

rehearsal of the failures of media science, at least in the US.

\section{Education or information?}

One longstanding point of contention between scientists and journalists revolves around the role of the media in communicating science. Scientists expect science education and scholarly communication as they understand it. Journalists see their role as informing and criticising as well as entertaining. While at least in Australia the divisions are less marked than in the past due partly to scientists' increasing engagement with the media and the efforts of science communicators to assist scientists in presenting themselves and their work, science news stories can still resort to stereotyping, 'breakthrough' proclamations and sensationalist 'shock-horror' predictions of doom and disaster - the latter especially from journalists ignorant about or hostile to science. Nevertheless there are many good science stories (in all senses of that term) across all media in Australia even if public broadcasters/television and broadsheet newspapers carry almost double the content of commercial and tabloid media (for details of the analysis, see Reed, 2002). With the concentration of media ownership, however, this means that extensive coverage is available to limited audiences (AB demographics) in the major capital cities as the national daily carries fewer stories than the other quality broadsheets.

Commitment to informing publics can result in paradoxical outcomes. On one hand it can produce some of the best critical information available to the public. On the other hand an uninformed and uncritical commitment to fostering democratic science debate can lead non-specialist journalists to see science stories as invariably requiring sensationalist investigative techniques. This is not to equate 'sensationalism' with investigative techniques. It remains a matter of skill/ability to make informed judgments as well as to argue for them with editors. While investigation is justified in the case of junk/fake/ pseudo-science and is understandable in the context of over-hyped corporate PR and the growth of commercial-in-confidence public sector research as a result of increasing public-private partnerships, not all science stories and even all private sector and private sector funded research departs from the canons of science. Scientists now are unlikely to be corrupted much more than other citizens whose professional activity requires them to work in similar contexts. Science probably retains about the same proportion of charlatans as in the past. As I indicated above, many scientists and other academics are now required to access this type of funding or undertake only research that can be accommo- 


\section{THE PUBLIC RIGHT TO KNOW}

dated with normal university resources that are in decline. They retain their commitments to openness and publication of results and would be prepared to resist pressures to suppress or conceal results unwelcome to industry partners.

Much science journalism in the daily press is sourced from the major international prestigious peer reviewed journals such as Nature, Science and other major medical journals with similar status. Reputable magazines such as New Scientist also provide leads. While not ensuring complete confidence in the conclusions, a fairly high level of reliability/validity/credibility can be assumed. Quality broadsheets increasingly welcome these stories as a 'change of pace' from other doom and disaster stories such as floods, earthquakes, murder and other crime stories, particularly in the era of 'war on terrorism' While breaking science news stories can be presented as 'breakthrough' sensationalism, where specialist science (or otherwise thoughtful) journalists adopt an 'issues' approach and seek additional input and make careful considered judgments about their research, these stories can be informative about scientific processes and developments allowing audiences to follow, participate and even demand public forums and the right to contribute. This type of journalism is still fairly limited. It requires at least a general awareness of science, an ability to read and assess scientific literature including statistics and risk evaluation, an engagement with the connections between scientific, economic and legal questions as well as the skills to be able to package them in media terms as informative, interesting, even entertaining stories.

This type of approach is time-consuming which is also one of the reasons cited for the observed decline in high quality in-depth investigative journalism. Time constraints have always been a factor in news reporting and despite the speeds of new technologies they remain, in part due to human resource constraints. It is particularly acute in relation to science reporting where one specialist is required to cover all stories and they need to absorb and analyse a great deal of esoteric information, contact a range of experts and compare and evaluate differing opinions. Additionally, it takes time to get appropriate and succinct comment on the record to accompany published material. Some scientific research is too technical and arcane to be amenable to media stories. Nevertheless, experienced journalists including non-scientists claim that there are very few scientific developments that cannot be presented in the media in an informative, accessible and even entertaining way. Where newspapers (such as quality broadsheets) employ a number of specialists (eg, in science, medicine, health, or the environment) in a team, this can go some way to 
alleviating the time pressures but there is often still too little time for a detailed, in-depth investigative approach.

Magazine programs on television such as the old Quantum and currently Catalyst (both produced by the Australian Broadcasting Corporation [ABC]) have much in common with issues journalism which includes both features and magazine articles in the daily press. They allow for some detail in presenting stories as well as a range of opinion and critical assessment. Other stand-alone documentaries (provided they don't succumb to the 'six-year-old with ADD' level) can also provide informative and entertaining content. Some of the more hyped 'zany' promotional programs directed to young people, on the other hand, could alienate as many young people as they attract due in part to excessive attempts to pick the most outlandish, sexy fragments (sometimes literally) of scientific knowledge. They also tend to be addressed to the typical interests of boys/young men rather than including topics that would appeal to both genders and/or the typical interests of girls/young women who may be contemplating science careers. Quality magazine and documentary programs and issues journalism, however, remain outside of the framework of science education desired by many scientists. It is likely that the media could never provide this type of content because it does not fit the 'story' format.

Given the dissatisfaction expressed by scientists about media coverage in research studies, it is interesting to note that science writers report that scientists 'never ring up' with stories - 'only the loonies ring up'. 'Loonies' is used here with intent and not as a derogatory term for alternative knowledges and practitioners outside the mainstream of western science and including some recent inclusions such as acupuncture which is now taught in universities. In the context of interview discussion, it refers to individuals who present as seriously deluded not only about their 'discoveries' but also about their own identities. Experienced science journalists are able to distinguish these pseudoscience stories (or worse) from mainstream science and alternative approaches and to advise editors with little or no scientific background who find them attractive, not to publish, sometimes by refusing to write. This is hardly suppression; rather it ensures that these media do not participate in the most damaging stories that raise false hopes for vulnerable citizens. Scientists who believe they have stories that should be told but find the mainstream media inaccessible could seek alternative/community media. This is not to say these would necessarily be willing to run science education per se. Nevertheless, it is interesting that many scientists who report or complain about lack of media 
attention have so few ideas about addressing/accessing avenues for public debate.

While the media are unlikely to be willing to participate in public science education, what the media can do is to provide a very high level of information about science, its processes and developments. With care, media stories about science can be produced by broadly educated non-scientists with the skills outlined above. These stories are not about promoting science or scientists but are an exercise in critical information sharing. Hence, they are a basis for citizens to form their own assessments of scientific developments. Science is now inextricably entwined with all aspects of living: work and employment, consumption, health and well-being. Shorn of its mystique and eye-glazing detail it is - or at least can be made - accessible to a generally well-educated public which is increasingly the case in late modernity. More of the already published critical/informative/entertaining issues of science journalism would go some way to sensitising the public about the myriad ways science impacts on their lives and encourage community debate. This approach would then prepare the ground for those instances where investigative journalism is critical to mobilizing public debate and influencing the direction of decisionmaking. Whether that is achievable with the current media structure is open to question but recognising that it does happen is a basis for encouraging more.

To give just one example here: stem cell research is one recent contentious topic. Yet it has been presented in the media as an issue for debate. Clearly this is a very complex area of genetics and one that raises ethical and legal questions. While some scientists and others with opposing value-positions are no doubt unhappy about the policy decision made, community views were at least taken into account.

Science policy, however, is an under-developed area of media science reporting. This is because policy decisions are normally made in the context of the Parliament by government ministers. These topics are interrogated by Parliamentary press gallery journalists. While highly informed politically and skilled in the art of questioning politicians, they are less familiar with science. Specialist science journalists are not in a position, and lack the requisite skills. to engage with the political decision-makers but have highly developed scientific knowledge. Science policy remains an area that 'falls between two stools' and remains under-developed. This therefore remains a constraint on an important aspect of informed community debate about science.

Having advocated issues rather than investigative journalism as the

98 PACIFIC JOURNALISM REVIEW 10 (1) 2004 
normal approach to the reporting of science does not mean that investigative techniques have no place in science reporting. Indeed, there are many similarities in terms of research and evaluation of material. With the blurring of the old boundaries such as public/private; government/corporate etc., and the growth of 'commercial-in-confidence' research funding there is a need for the conventional investigative approach with its hard-hitting stories that reveal fraud and corruption in some instances. Apart from those esoteric aspects of science that require detailed technical knowledge unsuitable for media presentation, there are untold stories in science that probably ought to be told such as the impact of chemicals in the environment and on public health, ongoing analysis of public health data such as cancer clusters, the world-wide water crisis, exploitation of developing countries' plant resources without compensation, choices in medical scientific research, selection of embryos for social purposes and the regulation of science itself. Some research on these topics would reveal whether or not they could be addressed as straight 'objective' reporting, issues journalism topics or matters for investigative journalism. They are all topics where a case could be made for a public right to know in the interests of democratic processes.

\section{Conclusion}

In summary, there are long-standing differences in vocational commitments by scientists and journalists which result in tension and conflict surrounding the media reporting of science. Scientists' desires for scholarly communication and science education in the media are unlikely to be satisfied but there is much critical, informative and entertaining science reporting which is and could be extended to form the basis of enhanced public understanding about science. They would allow engagement in debates on the ways scientific knowledge and developments have an impact on almost all aspects of life in late modernity. An issues approach to journalism which would extend to investigative approaches where research showed them to be justified would best facilitate these goals. More creative strategies need to be developed to produce more informed and critical coverage of science policy issues. This requires both broadly educated journalists, including at least some with science backgrounds. More importantly, it relies on a commitment of resources from media organisations. While hopeful for the former, given developments in journalism education, the latter is less likely with current media ownership structures. Those seeking to promote science in the media 


\section{THE PUBLIC RIGHT TO KNOW}

might adopt some of the techniques outlined in this paper and also engage more directly in seeking to extend opportunities for science communication to wider audiences via mainstream and alternative media.

\section{References}

Alic, M. (1986). Hypatia's Heritage: A History of Women in Science from Antiquity to the Late Nineteenth Century. London: Women's Press.

Burns, T. (2001). What is Australia's most pressing science communication need? A survey of the Australian Science Communicators 2000. Paper to '2001: A Science Odyssey',2nd National Conference of Australian Science Communicators, Sydney 23-26 September 2001.

Busch, J.(2001). Will they read it? Will they understand? Chemical Innovation, 31(5): 29-35.

Downie, L. Jr (1976). The New Muckrakers. Washington: New Republic Book Company.

Haraway, D. (1997). Modest_Witness@Second_Millenium.Female Man_Meets_Oncomouse: Feminism and Technoscience. New York: Routledge.

Hartz, J.\& Chappell,R.(1997).Worlds Apart: How the Distance Between Science and Journalism Threatens America's Future. Nashville, TN: First Amendment Centre. Hermanowicz, J.C. (1998). The Presentation of Occupational Self in Science. Qualitative Sociology, 21(2): 129-48.

Henderson, G. (2003, August 19). The warning sounded to whistleblowers everywhere. Sydney Morning Herald, p.11.

Hotz, R.L. (2003). The Difficulty of Finding Impartial Sources in Science. Nieman Reports, 56(3): 6-7.

Lloyd-Smith, M. (2002). Rights and Wrongs of Knowing in Chemical Conflict. In W. Bacon and C. Nash (eds) PR2K One: Selected Papers and Proceedings (pp 75102). Sydney: Australian Centre for Independent Journalism.

Perlman, D. (1974). Science and the Mass Media. Daedalus, 103(3): 207-22.

Peters, H.P. (1993). In Search for Opportunities to Raise 'Environmental Risk Literacy'. Toxicological and Environmental Chemistry, 40:289-300.

Peters, H.P. (1995). The Interaction of Journalists and Scientific Experts: Co-operation and Conflict between two Professional Cultures. Media, Culture and Society, 17(1): 31-48.

Reed, R. (2001). (Un-)Professional discourse?: Journalists' and scientists' stories about science in the media. Journalism, 2(3): 279-298.

Reed, R. (2002). From 'gee whizz' to 'shock-horror': The limited frameworks of science journalism. Australian Journal of Communication, 29(3): 43-56.

Rensberger, B.(2000). Why Scientists Should Cooperate with Journalists. Science and Engineering Ethics, 6(4): 549-52.

Rosenfeld, M. (2003).Canuck-Do Higher Education.Australian Universities Review, 46(1): 24-31.

Smith, D. (2003, September 10). Top scientific honour for Mr T Cell/Teacher's hands- 
on approach brings applause. The Sydney Morning Herald, p. 2.

Sobel,D.(1995).Longitude: The True Story of a Lone Genius Who Solved the Greatest Scientific Problem of His Time. London: Fourth Estate Limited.

Tumber, H. (1993). 'Selling Scandal': Business and the Media. Media, Culture and Society, 15(3): 345-61.

Walker, G. (2000). Journalism and Science: Can Communicators Bridge the Gap?. Australasian Science, 21(3): 40-2.

Wertheim, M. (1995). Pythagoras' Trousers: God, Physics, and the Gender Wars. London: Fourth Estate.

Winchester, S. (2001). The Map that Changed the World: The tale of William Smith and the Birth of a Science. London: Viking.

Zuel, B. (2003, August 25-31). Review of: As it Happened: The Day the Earth Nearly

Died. The Sydney Morning Herald, The Guide, p.20.

Dr Rosslyn Reed is Honorary Research Associate in the Faculty of Humanities and Social Sciences, University of Technology, Sydney. An earlier version of this article was presented to the third Public Right to Know (PR2K) Conference, University of Technology, Sydney, 17-19 October 2003. The research on which this article is based was supported by a UTS Industry/Link Research Grant to Rosslyn Reed, Tony Baker and Gael Walker with Louise McMahon, Public Affairs Manager of DuPont, as industry partner. Additional funding came from DuPont. Vicki Karaminas, Lynne Irvine and Jane Virag provided research assistance.The industry partner's interest was in resources to improve science reporting (i.e., an annotated bibliography) and publication in refereed journals. There were no commercial-in-confidence provisions. I wish to thank also those anonymous scientists, science journalists and practising and academic journalists who participated in focus groups and semistructured interviews.The author is solely responsible for the approach adopted in this article.

Rosslyn.Reed@uts.edu.au 